\title{
Some prospects for the use of ash and slag wastes of coal power plants for production of building materials
}

\author{
Fedor Bryukhan ${ }^{1, *}$ \\ ${ }^{1}$ Moscow State University of Civil Engineering, Department of Engineering Survey and Geoecology, \\ Yaroslavskoe sh. 26, 129337 Moscow, Russia
}

\begin{abstract}
Coal-fired thermal power plants (TPP) generate large amounts of ash and slag wastes (ASW), therefore ecological problems related to ASW storage and disposal for such power plants come to the fore. To obtain new data on ASW properties analysis of a number of ASW samples from ash dump No. 4 of Cherepet' TPP was carried out as part of engineering surveys. The purpose of this study included determiantion of the ASW granulometrical and mineralogical composition, as well as their physical and chemical properties. During field works 4 ASW samples were taken from the surface layer of the ash dump plus one sample of ash froth for further laboratory analysis. Laboratory analysis enabled determination of the granulometrical, mineralogical and chemical composition of ASW. Assessment of the ASW corrosiveness toward various materials determined necessary limitations in utilization of ASW-based bulding materiasls in contact with steel and aluminum. The content of natural radionuclides of $\mathrm{K}^{40}, \mathrm{Ra}^{226}$, $\mathrm{Th}^{232}$ and man-made $\mathrm{Cs}^{137}$ in ASW was determined. The detected increased activity of $\mathrm{Ra}^{226}$ and $\mathrm{Th}^{232}$ necessitates additional studies of radon and thoron emissions from ASW. Microspheres recovered from ash froth during ASW utilization have special usage value.
\end{abstract}

\section{Introduction}

It is known that coal-fired thermal power plants (TPPs) produce large amounts of ash and slag wastes (ASW). Coal-fired TPP in Russia produce about $30 \mathrm{Mt}$ of ASW per year, not more than $10 \%$ of which are recycled $[1,2]$. In this regard, ecological problems related to ASW storage and disposal for such power plants have top priority $[1,3,4]$.

ASW have many properties typical for different kinds of natural mineral raw materials. Therefore, they have an undeniable resource potential for production of various building materials $[1,5,6]$. In many cases, wastes with similar properties can be interpreted as an equivalent of natural raw materials with consumer properties, and this is also true for ASW. That is why along with the term "ASW» we can also use another definition - «ash and slag materials»». Considering large amounts of ASW, there is a range of promising directions of their utilization $[1,4,7]$, including production of cement, concrete, cinder-concrete blocks,

* Corresponding author: pniiis-gip@mail.ru 
bricks, microspheres, road construction. Implementation of the above methods of ASW usage will enable conservation of land resources, used for slag disposal areas, saving of natural raw materials and improvement of ecological conditions.

To obtain new data on ASW properties analysis of ASW samples from ash dump No. 4 of Cherepet' TPP was carried out as part of engineering surveys carried out for increasing the ash dump capactiy [8]. The purpose of this study included determiantion of the ASW granulometrical and mineralogical composition, as well as their physical and chemical properties.

\section{Sample collection and laboratory analysis}

The Cherepet' TPP is located in the Tula region, on the Cherepet' River, north-west of Suvorov. Its current installed output power, generated at 8 power units, is $1735 \mathrm{MWt}$. The power plant works on the Kuznetsk basin coal. The ash and slag handling system is hydraulically operated. The surface area of the ash and slag dump is about 150 ha.

The map of the ash dump and sampling points are shown in Figure 1. During the engineering survey, 4 ASW samples were taken from the surface layer of the ash dump (0$10 \mathrm{~cm}$ ) plus one sample of ash froth for further laboratory analysis.

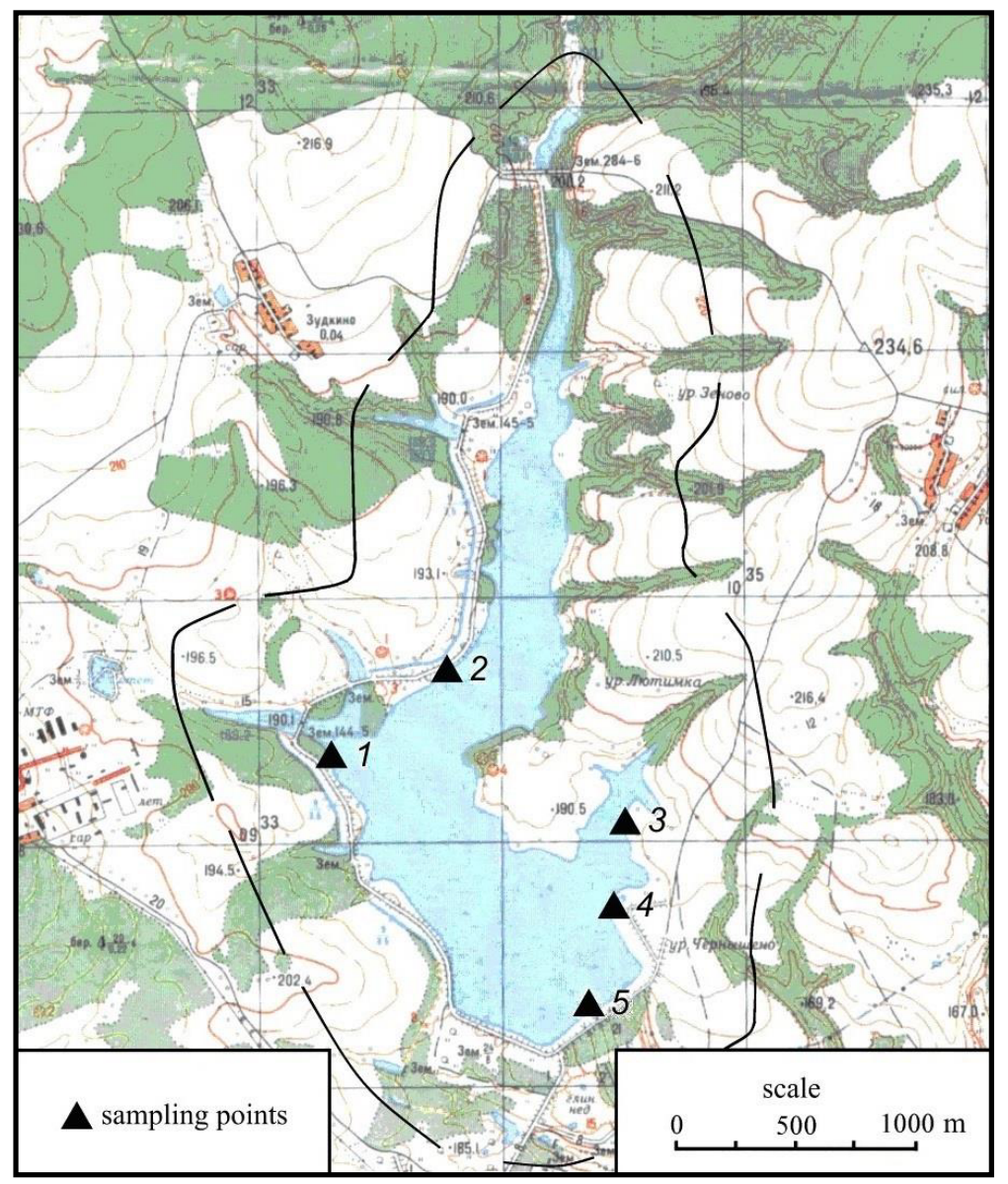

Fig. 1. Locations of ash (1-4) and ash froth (5) sampling points. The dotted line shows the sanitary protection zone of the ash dump. 
The following studies were performed during the laboratory analysis:

- granulometric analysis;

- X-ray phase analysis;

- analysis of ASW corrosion activity toward different materials;

- chemical composition analysis;

- radionuclide composition analysis.

Laboratory studies were conducted in the Production and Research Institute for Engineering Survey in Construction, the All-Russian Research Institute of Mineral Resources, the Russian State Geological Prospecting University, the Center of State Sanitary and Epidemiological Surveillance in Moscow.

\section{Results and discussion}

\subsection{Granulometric composition}

Average density of ash particles was $2.35 \mathrm{~g} / \mathrm{cm}^{3}$. Their statistical size distribution according to laboratory analysis of 4 samples is shown in Table 1. It is found that ash depositions belong to the dust sand category. According to the Table 1, the share of large particles above $50 \mu \mathrm{m}$ is $52.8 \%$, mid-size particles of $5-50 \mu \mathrm{m}-46.2 \%$, fine particles (less than 5 $\mu \mathrm{m})-1.0 \%$. In ash dump areas not covered by water, medium-size and fine particles (less than $50 \mu \mathrm{m}$ ) are blown off from the ash dump surface.

Table 1. Size distribution of ash particles.

\begin{tabular}{|c|c|c|c|c|c|c|}
\hline Size, $\boldsymbol{\mu m}$ & $<5$ & $5-10$ & $10-50$ & $50-100$ & $100-250$ & $250-500$ \\
\hline Distribution, \% & 1.0 & 8.9 & 37.3 & 20.0 & 7.5 & 2.5 \\
\hline
\end{tabular}

\begin{tabular}{|c|c|c|c|c|c|}
\hline Size, $\boldsymbol{\mu m}$ & $500-1000$ & $1000-2000$ & $2000-5000$ & $5000-10000$ & $>10000$ \\
\hline Distribution, $\%$ & 1.1 & 3.7 & 9.3 & 6.2 & 2.5 \\
\hline
\end{tabular}

\subsection{Mineralogical composition}

Samples from the ash dump passed the X-ray phase analysis on DRON-3 diffractometer. The following minerals were found in the samples: quartz, hematite, mullite and glass, demonstrating halos on X-ray images. Quartz is present in Kuzbas coals and appears as a detritus mineral. Mullite, hematite and glass occur in the process of coal combustion. A light fraction in the form of specific hollow microspheres of up to $500 \mu \mathrm{m}$ prevails in ash froth.

\subsection{Chemical properties and corrosion activity}

Based on ASW chemical analysis, it was found that they contain a large amount of $\mathrm{Pb}$, moderate quantities of $\mathrm{Mn}$ and $\mathrm{B}$ and fractional amounts of other chemical elements. The content of active forms of $\mathrm{Zn}, \mathrm{Co}, \mathrm{Cu}, \mathrm{Ni}, \mathrm{Cr}$ is considerably below the maximum permissible values. It is important to emphasize that concentrations of benzo[a]pyrene in the collected samples are very low. 
In terms of perspectiveness of ASW application in manufacture of building materials, it is important to determine their corrosion activity toward materials that will be in contact with ASW-based building materials. In this regard, relevant laboratory studies were performed in order to determine the degree of ASW corrosiveness toward different materials. Corrosiveness analysis results are show in Table 2.

Table 2. ASW corrosiveness toward different materials. Water extract mineralization is $240 \mathrm{mg} / \mathrm{dm}^{3}, \mathrm{pH} 8.6$.

\begin{tabular}{|c|c|}
\hline Materials in contact with ASW & Corrosiveness level \\
\hline steel & medium, high \\
\hline armature of concrete elements & low, medium \\
\hline lead & low, medium \\
\hline aluminum & medium, high \\
\hline concrete & non-corrosive \\
\hline
\end{tabular}

Thus, the findings indicate the need for limitations in utilization of ASW-based bulding materiasls in contact with steel and aluminum.

\subsection{Radionuclide composition}

The ash samples were also analyzed for the content of natural radionuclides $\mathrm{K}^{40}$, $\mathrm{Ra}^{226}$, $\mathrm{Th}^{232}$ and man-made $\mathrm{Cs}^{137}$. Laboratory analysis have not detected any radioactive contamination in the ASW samples, but found relatively high activity of radionuclides $\mathrm{Ra}^{226}$ and $\mathrm{Th}^{232}$. The expert opinion of the Center of State Sanitary and Epidemiological Surveillance in Moscow states that in case of ash utilization in production of building materials it is necessary to assess radon and thoron emissions from ASW.

\subsection{Microspheres}

As stated above, a light fraction in the form of small hollow microspheres of up to $500 \mu \mathrm{m}$ prevails in the ash froth. They are relatively rare in the ash - only a few percent. The microspheres are characterized by a range of useful properties contributing to their wide application. Particularly, their dry density is very low - about $130 \mathrm{~kg} / \mathrm{m}^{3}$ at an average. They serve as the basis for low-cost fireproof bricks, heat and sound insulating materials, foam materials. Building materials manufactured using the microspheres also have resistance to vapor penetration, screening capacity against ionizing radiation effects, a high degree of adhesion with many materials (concrete, brick, timber, etc.).

\section{Conclusions}

- Granulometric analysis of ASW samples showed that the average content of large particles over $50 \mu \mathrm{m}$ is $52.8 \%$, mid-size particles of $5-50 \mu \mathrm{m}-46.2 \%$, fine particles (below $5 \mu \mathrm{m}$ ) $-1.0 \%$. Quartz, hematite, mullite and glass particles were detected in the samples.

- According to ASW chemical analysis, they contain a large amount of $\mathrm{Pb}$, moderate quantities of Mn and B and fractional amounts of other chemical elements. The content of 
active forms of $\mathrm{Zn}, \mathrm{Co}, \mathrm{Cu}, \mathrm{Ni}, \mathrm{Cr}$ is considerably below the maximum permissible values. The content of benzo[a]pyrene in the ash and ash froth is negligible.

- ASW corrosiveness toward different materials in contact with ASW was analyzed. The assessment showed that the degree of ASW corrosiveness toward the armature of concrete structures and lead is low and medium, steel and aluminum - medium and high. At the same time, ASW are not corrosive to concrete.

- Laboratory tests of ASW samples detected no radioactive contamination of ASW. However, they revealed a relatively increased activity of $\mathrm{Ra}^{226}$ и $\mathrm{Th}^{232}$. This necessitates conduction of assessments of radon and thoron emissions from ASW, if they are used in manufacture of building materials.

- Microspheres produced in the process of coal combustion have very useful properties that enable their usage in production of building materials.

- The findings indicate a good outlook and advisability of large-scale utilization of ASW.

\section{References}

1. Yu.K. Tselykovsky, New in the Russian Power, 4, 1542 (2002)

2. Yu.K. Tselykovsky, Energy: Economy, Technology, Environment 4, 2734 (2006)

3. V.Ya. Putilov, Energetik, 4, 3740 (1999)

4. V.Ya. Putilov, Ecology of Energy (National Research University «MPEI», Moscow, 2003)

5. A.I. Abramov, D.P. Elizarov, A.N. Remezov et. al., Increasing of TPP environmental safety (National Research University «MPEI», Moscow, 2001)

6. V. Knat'ko, M. Knat'ko, E. Scherbakova, Ecol. and Sust. Devel. 2, 3032 (2004)

7. M. Hanzelova, L. Florekova, B. Stehlikova et al., Proc. of the 6-th Conf. on Envir. and Min.1 Proc., Ostrava, 431-436 (2002)

8. A.F. Bryukhan, F.F. Bryukhan, A.D. Potapov, Engineering and environmental survey for the construction of thermal power plants (ASV Publishing House, Moscow, 2010) 